\title{
Roberte Tomassone, Pour enseigner la grammaire - Roberte Tomassone et Geneviève Petiot, Pour enseigner la grammaire II
}

\section{Rachele Raus}

\section{(2) OpenEdition Journals}

Édition électronique

URL : http://journals.openedition.org/studifrancesi/36956

DOI : 10.4000/studifrancesi.36956

ISSN : 2421-5856

Éditeur

Rosenberg \& Sellier

\section{Édition imprimée}

Date de publication : 1 juillet 2005

Pagination : 219

ISSN : 0039-2944

\section{Référence électronique}

Rachele Raus, «Roberte Tomassone, Pour enseigner la grammaire - Roberte Tomassone et Geneviève Petiot, Pour enseigner la grammaire II », Studi Francesi [En ligne], 145 (XLIX | I) | 2005, mis en ligne le 30 novembre 2015, consulté le 19 avril 2021. URL : http://journals.openedition.org/studifrancesi/36956 ; DOI : https://doi.org/10.4000/studifrancesi.36956

Ce document a été généré automatiquement le 19 avril 2021.

\section{cc) (†) $\odot$}

Studi Francesi è distribuita con Licenza Creative Commons Attribuzione - Non commerciale - Non opere derivate 4.0 Internazionale. 


\title{
Roberte Tomassone, Pour enseigner la grammaire - Roberte Tomassone et Geneviève Petiot, Pour enseigner la grammaire II
}

\author{
Rachele Raus
}

\section{RÉFÉRENCE}

ROBERTE TOMASSONE, Pour enseigner la grammaire, Paris, Delagrave, 2002, pp. 318.

Roberte Tomassone et Geneviève Petiot, Pour enseigner la grammaire II, Paris, Delagrave, 2002, pp. 287.

1 L'œuvre se compose de deux livres, le premier théorique, le second d'analyses empiriques de textes généralement littéraires, mais pas exclusivement.

2 Le premier livre se veut une "grammaire de discours» en même temps qu'une "grammaire de texte». L'A. structure l'ensemble en cinq parties. Dans la première, il présente l'énonciation sous les aspects des déictiques, de la modalisation, des actes de parole, du discours rapporté et de la différence opérée par Benveniste entre histoire et discours. Dans la deuxième partie, suivant entre autres l'approche d'Adam, il introduit la dimension textuelle, notamment le couple thème / propos et les différents types de progression thématique. La troisième partie considère la dimension de la phrase, partant de la distinction entre phrase de base et complexe. La quatrième partie considère les différents groupes qui composent la phrase (verbal, nominal, ...). Les manipulations de la structure phrastique sont considérées comme un critère valable pour retracer la présence de certains éléments et formes. Dans la cinquième partie, les constituants sont analysés à partir de classes. Le critère syntaxique est toujours conjugué avec un critère sémantique, les deux contribuant à éclairer certaines 
différences constitutives entre éléments somme toute très proches (épithète apposition, formes verbales, ...).

3 Le second volume (avec CD-rom) fournit des exemples d'analyse de textes, utilisant les notions théoriques exposées dans le premier. Ce livre complète également l'œuvre générale, fournissant des approfondissements de certaines questions, notamment pour ce qui est de l'analyse du discours (autonymie, interdiscours, ...), et pour ce qui est des typologies des textes à partir d'un critère empirique. Le CD-rom permet d'annexer les nombreux textes utilisés pour l'analyse. 